\title{
ALCANCES SOBRE LA RESPONSABILIDAD CIVIL EN EL CASO DE LAS SOCIEDADES MERCANTILES
}

\author{
Ana María Aranda Rodríguez
}

\begin{abstract}
Resumen
La imputación de los daños producidos por las sociedades mercantiles a través de sus órganos constitutivos, ha tenido diversos enfoques, tanto en el ámbito doctrinario como jurisprudencial. El presente artículo pretende hacer algunas reflexiones y dejar sentado que si la indicada persona jurídica ocasiona daños por los actos de sus órganos constitutivos, no se refiere a un actuar por otro, y es dicha sociedad quien debe asumir la responsabilidad, por ende no resultan de aplicación las normas referidas a la responsabilidad del subordinado, sino más bien las normas que contienen el principio de no causar daño a nadie.
\end{abstract}

Palabras clave: Daños - Sociedad mercantil.

\begin{abstract}
The imputation of the damages produced by the mercantile societies through its constituent organs, it has had diverse approaches, as much in the doctrinary scope as in the legal. The present article tries to make some reflections and to establish that if the indicated legal person causes damages by the acts of its constituent organs, these are not refered to the acting of others, and it is this society that must assume the responsibility, therefore is impossible the application of the norms that is referred to the responsibility of the subordinate, in that situation there must be applied the norms that contain the principle of not causing damage to anybody.
\end{abstract}

Keywords: Damages - Business association.

\section{Sumario}

1. Conceptos fundamentales del derecho civil. 2. Órganos constitutivos de las sociedades mercantiles -sociedades anónimas- y los supuestos regulados de responsabilidad civil. 3. El artículo $1981^{\circ}$ del Código Civil y la denominada Responsabilidad Vicaria. 4. Conclusiones.

* Vocal Titular de la Corte Superior de Justicia de Lima. Docente universitaria. 


\section{CONCEPTOS FUNDAMENTALES DEL DERECHO CIVIL}

Esta sumaria revisión de conceptos fundamentales no pretende ser la palabra final y definitiva de lo que son los diversos institutos civiles que presentamos a continuación. Se exponen con finalidad de hacer más comprensible el presente trabajo.

\subsection{NOCIÓN DE SUJETO DE DERECHO}

Sujeto de derecho viene a ser todo aquel individuo o entidad, capaz de ser sujeto de derechos y obligaciones ${ }^{1}$. Sin embargo, algunos autores consideraban que el hombre individualmente considerado se identificaba ontológicamente con lo que es un sujeto de derecho, lo cual no es totalmente cierto, porque las personas jurídicas, aquellas asociaciones de personas unidas por un fin común, también constituyen sujetos de derecho.

La definición que ha dado Kelsen ${ }^{2}$ respecto de los sujetos de derecho, entendidos como centros unitarios de derechos y deberes, con base en la Teoría Pura del derecho, ha llevado a este autor a sostener que el concepto de persona o sujeto de derecho es sólo un recurso mental artificial ${ }^{3}$, persona o sujeto de derecho son para Kelsen, expresiones unitarias de una pluralidad de derechos y deberes.

\subsection{DEFINICIÓN DE PERSONA JURÍDICA}

Ferrara ${ }^{4}$ establecía que junto a las personas naturales son reconocidas por el derecho, otros sujetos jurídicos que desde el momento de su inscripción en el Registro respectivo se constituyen como un centro ideal de imputación de deberes y derechos.

El orden jurídico por medio de la regulación, ha convertido en jurídicas las intenciones de los hombres organizados en torno a un fin; pues éstos se mueven y obran cual si fueran seres humanos ${ }^{5}$, porque para el cumplimiento de sus fines ${ }^{6}$ se ponen en relación con otros o con otros grupos de personas, pudiendo adquirir derechos y contraer obligaciones, e incluso incurrir en responsabilidad al producirse un daño.

El reconocimiento de la persona jurídica, tiene por objeto producir una separación de la esfera jurídica de este sujeto de derecho de la esfera jurídica de los miembros que la componen o están a su servicio ${ }^{7}$. El patrimonio de las personas jurídicas no es de los miembros que la integran, ni la responsabilidad de la persona jurídica recae personalmente sobre los integrantes de la misma. 
Autores como Gierke ${ }^{8}$ con su Teoría Orgánica, ven en la persona jurídica una vida autónoma y una voluntad propia, de allí un particular interés en que la persona jurídica sea considerada como sujeto de derecho.

\subsection{CAPACIDAD DE LA PERSONA JURÍDICA}

La persona jurídica en tanto sujeto de derecho, posee la capacidad de goce, es decir la aptitud para ser el centro de imputación de derechos y obligaciones, al constituir un sujeto de derecho y por ende titular de relaciones jurídicas ${ }^{910}$.

La actuación de los órganos societarios, en especial de la sociedad mercantil, ésta determinada por lo que se entiende como representación orgánica ${ }^{11}$. Siendo ello así, la limitación en la actuación de un órgano societario ${ }^{12}$, desde la organización de éste, podría tener como resultado la ineficacia del acto celebrado frente a la sociedad mercantil.

José Puig Brutau ${ }^{13}$ define la capacidad jurídica como la aptitud de la persona para ser titular de las relaciones jurídicas que le afectan, y este concepto de la capacidad jurídica también resulta valedero cuando se aplica a las personas jurídicas. Más aún cuando para apreciar la capacidad jurídica de este sujeto de derecho deben apreciarse en conjunto sus estatutos, en especial cuando hablamos de sociedades mercantiles.

La exigencia de que conste el fin u objeto de la persona jurídica, ha ocasionado que se piense que la capacidad jurídica de las mismas sólo se extiende a la realización de aquellas actividades que coadyuven para el fin que determinó su creación, tesis que se fundamenta cuando se parte de la persona jurídica entendida como una ficción.

En consecuencia, la capacidad jurídica de las personas jurídicas es, al igual que las personas físicas, una cuestión de orden público, y por tanto, la determinación de esta capacidad jurídica viene establecida con carácter imperativo por el ordenamiento jurídico, lo cual en cierta medida se establece por el objeto o fin que se propone.

\subsection{REPRESENTACIÓN}

En el punto de origen de la teoría de la representación no hay nada más que un problema práctico, que consiste en hacer posible una colaboración entre miembros de una comunidad jurídica ${ }^{14}$, lo que se presenta como una situación de necesidad. 
Jorge Mosset Iturraspe ${ }^{15}$ entiende que solo la representación directa es la verdadera representación y como consecuencia de ello la define como el medio por el cual una persona realiza un acto jurídico a nombre de otro y para que los efectos se produzcan exclusiva e inmediatamente en el representado.

\subsubsection{La representación de una persona jurídica}

En la doctrina se ha discutido si las personas físicas que actúan en nombre o por cuenta de las personas jurídicas merecen ser calificadas como representantes o si son, por el contrario, órganos de este ente. Es por ello que ha surgido una posición ecléctica que nos presenta a la representación orgánica ${ }^{16}$, la cual nos parece la posición más adecuada en el caso de la persona jurídica, en especial de la sociedad mercantil.

La diferencia entre estos puntos de vista podemos apreciarlos bien en la teoría orgánica que concibe a la persona jurídica como un sujeto de derecho con plena capacidad de ejercicio, que actúa por medio de sus miembros u órganos, de tal manera que los actos realizados por dichos órganos dentro de su competencia, estatutos y demás se consideran imputados ${ }^{17} \operatorname{como}$ actos de la persona jurídica, de manera que no existe ninguna intermediación.

La persona considerada como órgano es la misma persona jurídica actuando. Según la teoría de la representación, la persona jurídica sería un sujeto incapaz de obrar por si mismo, que, a semejanza de lo que ocurre con los demás incapaces, necesita valerse de un representante legal. Respecto de esto último, creemos que el sentido de representante en cuanto a la persona jurídica no ha sido el de establecer que alguien sea quien desempeñe la especial capacidad de ejercicio de la persona jurídica, dado que la misma no puede actuar por si misma en el mundo físico. Creemos que este no es el sentido de la norma y que la representación en ese sentido estricto no se aplica en este caso especial.

La teoría organisista sostiene que el acto del órgano de la persona jurídica se considera como un acto de la persona jurídica, desde que es la persona jurídica actuando, lo que es una ficción como que la misma persona jurídica lo es. En ese sentido, el acto del órgano es, verdaderamente, el acto de la persona jurídica, al imputársele su realización.

Existen en nuestro ordenamiento suficientes elementos para hablar de la representación orgánica de las personas jurídicas, lo cual es claro en el Código Civil y en la Ley General de Sociedades; por ello, el actuar de una persona jurídica no se enmarca en el actuar por otro, pues es la misma persona jurídica la que despliega su actividad. Se debe tener en cuenta lo desarrollado por la 
representación orgánica, de especial aplicación para los casos de la persona jurídica, como el caso de la sociedad mercantil, en donde la existencia de los órganos de la sociedad y su especial actuar a través de personas físicas ocasiona que se imputen sus actos o negocios jurídicos a la misma.

\subsection{RESPONSABILIDAD CIVIL}

Giovanna Visintini ${ }^{1 \varepsilon}$ señala que la responsabilidad contractual resulta al final de cuentas una forma de ejecución forzada de la obligación que no ha sido cumplida o incluso en otros remedios, lo que la diferencia de la responsabilidad extracontractual, dado que ésta busca una sanción por un daño ocasionado, el cual es el resultado de la violación del deber general de no causar daño a nadie.

\subsection{NOCIÓN DE INDEMNIZACIÓN}

Para nosotros lo que interesa en el incumplimiento, cuando tratamos de responsabilidad contractual, como en la violación del deber general de no causar daño a nadie cuando se trata de responsabilidad extracontractual, es el resarcimiento que el responsable del evento dañoso debe efectuar a favor de la víctima del daño, lo cual se produce tanto en el supuesto contractual como extracontractual previsto en la normativa vigente, daño generalmente resarcido a través del pago de una suma de dinero.

\section{2. ÓRGANOS CONSTITUTIVOS DE LAS SOCIEDADES M ERCANTILES -SOCIEDADES ANÓNIMAS- Y LOS SUPUESTOS REGULADORES DE RESPONSABILIDAD CIVIL}

\subsection{EL DIRECTORIO ${ }^{19}$}

Órgano de representación y gestión de la sociedad mercantil, en especial la sociedad anónima, el cual es un órgano colegiado, ya que su número no puede ser menor de tres. Cabe precisar que la gestión no se hace individualmente, pues son las personas que ejercen el cargo de director, reunidas, quienes toman las decisiones y ejercen la facultad de gestión y representación de la sociedad de que se trate.

Al respecto, solo pueden ser directores las personas naturales, no las personas jurídicas. Asimismo, para ser director no se requiere ser accionista salvo lo prevea el estatuto, pero aún así, es conveniente que no lo sea, que sea técnico, que conozca el negocio y que sobre todo tenga conocimientos en cuanto a la marcha social de la sociedad de la que le toque ser director. 
El patrón de conducta de quienes ejercen el cargo de director se encuentra consignado en la Ley General de Sociedades en torno a un criterio de responsabilidad subjetiva abstracta, pues suponemos que el legislador ha considerado de difícil tarea el evaluar la responsabilidad concreta de los directores, lo cual corresponde en esencia a los jueces que aplican la ley al caso concreto. Es de esta manera, que el legislador establece "el patrón de conducta del buen padre de familia", criterio subjetivo, pero que en el ámbito societario presupone conocimientos técnicos, conocimiento del negocio, conforme lo establece el artículo $171^{020}$ de la Ley General de Sociedades; de allí que la diligencia de un ordenado comerciante y representante leal, sea un parámetro más estricto para apreciar la conducta del director.

Adicionalmente, conforme al artículo $166^{021}$ de la norma acotada: el cargo de director necesariamente es retribuido, lo cual es fijado en la junta general de accionistas cuando nombran al directorio. Modernamente adicional a la retribución fija se le dan opciones de compra de acciones, lo cual depende de los resultados de la marcha social, en el Perú las opciones están poco desarrolladas; sin embargo, conforme al artículo $166^{\circ}$ de la Ley General de Sociedades, el principal incentivo en el Perú es la participación en las utilidades, lo cual promueve que los directores tengan mayores incentivos en el desarrollo de la labor.

Sin perjuicio de lo antes señalado, que el cargo de director sea remunerado no significa que quienes ejercen este cargo se encuentren en una relación de subordinación laboral respecto de la sociedad en la cual integra el órgano colegiado, se trata de una retribución teniendo en cuenta que los directores pueden no ser accionistas.

Los directores individualmente no tienen poder relevante en la sociedad, solo actúan en las reuniones del órgano colegiado para adoptar acuerdos, no actúan diariamente, no pueden negociar a que trabajadores contratan, ni determinar que proveedores les proveerán de bienes o servicios, por eso necesitan que alguien actúe el día a día, lo cual corresponde a la gerencia.

\subsection{LA GERENCIA 22}

Es el órgano societario que ejecuta los acuerdos del Directorio, es el órgano de gestión que ve el actuar diario de la sociedad mercantil y por ello es siempre necesario que exista un gerente general, en el eventual caso de que exista más de un gerente.

La Gerencia General es el órgano societario que lleva adelante la actuación y 
ejecución de los acuerdos del Directorio. En ese sentido, de existir más de un Gerente, éstos son subordinados al Gerente General y limitados a funciones particulares como en el caso de un Gerente de Ventas.

La Gerencia, como órgano societario, constituye el brazo ejecutivo de la sociedad mercantil, en especial en la sociedad anónima; siendo lo típico del mismo que no se desempeñen estas funciones de manera colegiada como sería el caso del Directorio, ya que las decisiones cotidianas de la sociedad deben producirse de inmediato.

En ese sentido, las atribuciones del Gerente son fijadas de diversas maneras, por los estatutos, por la Junta General de Accionistas, por el Directorio o incluso fijadas en el acto mismo del nombramiento; sin embargo, es en el estatuto en que se consignan la amplitud de atribuciones de que goza, las mismas que dependen de la confianza que se le tenga.

Asimismo, al ser un cargo de confianza el Gerente puede ser removido en cualquier momento, por lo que no caben designaciones irrevocables, conforme lo establece el artículo $187^{023}$ de la Ley General de Sociedades.

El criterio para apreciar la responsabilidad de quien desempeña el cargo de Gerente es como en el caso del Directorio ${ }^{24}$ el de la responsabilidad subjetiva abstracta, el de un ordenado comerciante y leal representante, que es un grado superior al del buen padre de familia.

En el caso de la responsabilidad contractual tratándose de los actos en el campo civil, la culpa leve se presume; sin embargo, la sociedad mercantil constituye en su esencia una empresa riesgosa por naturaleza, y lo más razonable es que pueda equivocarse. En ese sentido, si la culpa leve fuera la norma, la sociedad estaría condenada a la inmovilidad, por ello se incurre en responsabilidad cuando existe culpa inexcusable, si actúa contra la ley, contra el estatuto o con dolo, conforme lo dispone el artículo $190^{025}$ de la Ley General de Sociedades.

2.3 TRATAMIENTO ACTUAL DE LA RESPONSABILIDAD CIVIL EN LAS SOCIEDADES M ERCANTILES: LAS SOCIEDADES ANÓNIMAS

\subsubsection{En el caso de El Directorio}

Los Directores son ilimitada y solidariamente responsables de conformidad con el artículo $177^{026}$ de la Ley General de Sociedades. Al respecto llama la atención que el tratamiento de la responsabilidad de este órgano societario, se 
efectué no desde la concepción de la teoría del órgano de la persona jurídica y por ende sea ésta la que responda frente al daño, sino que se distinga a los integrantes de la misma haciendo un análisis subjetivo de responsabilidad en la persona de sus integrantes.

Sobre el particular, cabe precisar que la responsabilidad es solidaria, respecto de los Directores que causaran el daño, por ello, en caso fueran tres, se podría pedir la indemnización a cualquiera de ellos como integrantes de este órgano colegiado o en su caso a todos.

Respecto del cumplimiento de los actos señalados en el segundo párrafo del artículo $177^{\circ}$ de la Ley General de Sociedades, debemos tener presente que habiendo optado la ley por la teoría organicista, no nos encontramos en supuesto alguno de mandato o de representación por parte de este órgano societario con respecto de la Sociedad Anónima, debido a que es la propia sociedad mercantil quien desarrolla sus actividades de dirección a través de este órgano, por lo que ante el incumplimiento de los miembros del Directorio de acuerdos adoptados que generen daños o ante la presencia de estos últimos, corresponde a la propia sociedad el resarcimiento, adicionalmente de las personas que constituyen el Directorio.

\subsubsection{La responsabilidad de Ios Directores y su tratamiento frente a los acreedores, según la Ley General de Sociedades}

Puede iniciarse la pretensión individual de responsabilidad de conformidad con el artículo $182^{027}$ de la Ley General de Sociedades, así como el establecimiento de las responsabilidades penales de los Directores de existir estas, de conformidad con el artículo $183^{02 \varepsilon}$ de la referida ley.

Las pretensiones indemnizatorias individuales, tienen como finalidad resarcir los daños y perjuicios generados en contra de los accionistas o algún tercero y pueden ser iniciadas directamente por éstos a mérito de lo dispuesto por el artículo $182^{\circ}$ de la Ley General de Sociedades.

Esta responsabilidad es distinta de los casos en que el perjuicio se produce contra el interés social. Aquí estamos frente a una lesión directa de los intereses de los accionistas o terceros, es decir, se trata de un daño directo.

Para ejercitar esta pretensión, debe acreditarse legitimidad, la producción del daño y el nexo causal que se configuraron por el actuar antijurídico de alguno o todos los miembros del Directorio. 


\subsubsection{El caso de La Gerencia}

El Gerente es solidariamente responsable con los miembros del Directorio de conformidad con el artículo $191^{029}$ de la Ley General de Sociedades.

Sobre el particular, debemos tener presente que la responsabilidad alcanza al Gerente que participa en los actos que decida el Directorio y que causen responsabilidad; incluso cuando conociendo de éstos actos no los comunicó oportunamente, como en el caso de los directores que asumiendo el cargo no comunicaran estas anomalías.

Sin perjuicio de lo antes señalado, a diferencia del caso de los directores no existe una norma como el artículo $178^{\circ}$ de la Ley General de Sociedades, que permita salvar la responsabilidad del Gerente, y ello nos señala un nuevo indicativo de la subordinación laboral en que se encuentra, en que si bien constituye un órgano societario de acuerdo a la normativa vigente, constituye también un subordinado en la estructura de la sociedad mercantil, lo cual ha traído no pocas confusiones como desarrollaremos más adelante.

\section{EL ARTÍCULO 1981 DEL CÓDIGO CIVIL Y LA DENOMINADA RESPONSABILIDAD VICARIA}

Como ya lo hemos apreciado, las sociedades mercantiles, por su especial capacidad de ejercicio actúan a través de órganos societarios, los cuales, si bien están integrados por personas naturales, no significa que nos encontremos frente a una persona distinta, sino frente a la misma sociedad mercantil.

Hasta este punto, que duda cabe, que la existencia de personas naturales en una organización de las características de una sociedad mercantil nos puede llevar a la confusión respecto del actuar por otro, que ya hemos apreciado en los puntos precedentes. Sin embargo, es justamente el actuar por otro lo que nos muestra la existencia de la responsabilidad vicaria, dado que el término vicario se deriva del latín vicarius, que como adjetivo significa, que tiene las veces, poder y facultades de otra persona o la sustituye, y como sustantivo, es aquella persona que da las órdenes regulares y autoridad de alguno de los superiores mayores, en caso de ausencia, falta o indisposición ${ }^{30}$.

El tema es pues, que nos encontramos en el artículo $1981^{031}$, con lo que se definió en su momento, por la exposición de motivos del Código Civil de 1984, como responsabilidad indirecta, por cuanto en la misma se atribuye responsabilidad al empleador por razón del daño producido por su empleado, dentro de las 
circunstancias que se indica, expresándose que ambos responsables lo son con responsabilidad solidaria ${ }^{32}$.

$\mathrm{Al}$ respecto, cabe precisar dos puntos que son sustancialmente importantes:

a) Los autores del Código Civil de 1984, cuando elaboraron el artículo $1981^{\circ}$ siempre sostuvieron que nos encontrábamos frente a una relación de dependencia respecto de un empleador, ergo, existiría entonces para el legislador de 1984 una relación de subordinación laboral, razón por la cual se le imputa a aquél, el daño producido haciéndolo responsable, cuando su dependiente fue el causante material del daño.

No debemos perder de vista, que ya es bastante complicado comprender que la sociedad mercantil realiza su objeto social por medio de los órganos societarios que la conforman, los cuales se encuentran integrados por personas naturales cuyo accionar será imputado a la citada sociedad mercantil, conforme lo hemos apreciado en los puntos precedentes. Siendo ello así, el supuesto que contiene el artículo $1981^{\circ}$, no resulta de aplicación frente a integrantes de los órganos societarios, "sino frente a dependientes, ajenos a la estructura interna de la sociedad mercantil, porque estos últimos se encuentran en una relación de subordinación frente a la sociedad mercantil."

Al respecto, cabe precisar que la Gerencia de una sociedad mercantil, específicamente en el caso de una sociedad anónima, constituye un órgano de representación y de gestión cotidiana de aquélla, conforme a la Ley General de Sociedades y por tanto, es la misma sociedad mercantil la que actúa cuando este Gerente realiza sus funciones habituales; sin embargo, también resulta, a la vez, ser un dependiente en el sentido laboral dado que percibe una remuneración, está sujeto a un horario de trabajo, ergo está sujeto a subordinación, control, fiscalización y sanción en cuanto al desarrollo de sus actividades.

Es por ello que nos encontramos frente a una imprecisión normativa en cuanto a si el Gerente puede ser considerado como un dependiente laboral, o si es un órgano societario. La respuesta, desde nuestra perspectiva, es que a pesar que el Gerente es un subordinado, al mismo tiempo es también un órgano societario. Pero para efectos de la aplicación de las normas de responsabilidad, en caso se haya producido un daño por parte de una 
sociedad mercantil, que actúa a través del Gerente no debe caerse en el facilismo de considerar únicamente el aspecto relativo a la dependencia laboral y aplicar sin hacer distingos el supuesto normativo contenido en el artículo $1981^{\circ}$ del Código Civil, puesto que se estaría desconociendo la Teoría Organicista que adopta la legislación societaria, y que preconiza que a través de estos se expresa la voluntad social y no solo del Órgano. En ese sentido, producido el daño a un tercero de buena fe que se materializa con la actuación de la Gerencia de la sociedad mercantil, no sería de aplicación el artículo $1981^{\circ}$ del Código Civil, sino que nos encontraríamos en un supuesto de responsabilidad directa de la sociedad mercantil.

b) Sostiene el legislador de 1984 que el artículo $1981^{\circ}$ del Código Civil es un caso de responsabilidad objetiva respecto del empleador.

Este es un razonamiento correcto, puesto que de producirse un daño por parte de un dependiente y por tanto producirse el supuesto de hecho de la norma, el daño sería solidario con el principal. En ese sentido, Juan Espinoza Epinoza señala con acierto, al citar a Monateri, que la responsabilidad de los principales y los dependientes, "desde la antigua fundación de la culpa in eligendo o in vigilando continúa hacia el reconocimiento del carácter objetivo de una responsabilidad que permanece siendo vicaria (en cuanto presupone la del dependiente), llega después a una fase en la cual el aspecto vicario desaparece (admitiéndose la aplicación normativa incluso cuando el autor del daño no responde personalmente) y llega finalmente a la responsabilidad directa (ya no vicaria de la empresa) por todos los daños ocasionados, aunque sean independientes de un comportamiento humano, por el proceso productivo" ${ }^{\prime \prime 3}$.

En el tema del presente artículo resulta de suma importancia reconocer, que si bien nos encontramos frente a un supuesto de responsabilidad objetiva, en el caso del artículo 1981, el mismo requiere de una ubicación adecuada, por ello nos remitimos al análisis señalado por Juan Espinoza Espinoza ${ }^{34}$ en cuanto a la aplicación del artículo $1981^{\circ}$ del Código Civil de 1984:

i) Una relación de subordinación: la cual debe ser restringida a lo que señaláramos en el punto precedente, que ésta no puede extenderse de manera lata a cualquier supuesto de dependencia.

ii) Que el subordinado ocasione un daño, para lo cual, con acierto Juan Espinoza Espinoza, señala que este daño producido por el dependiente estaría incurso en responsabilidad subjetiva, en donde se aplicaría el 
dolo o la culpa, lo cual tampoco descarta la aplicación del artículo $1970^{\circ}$, referido a la responsabilidad objetiva.

iii) Que exista una relación de causalidad adecuada, en los términos del Código Civil de 1984, por la cual el dependiente, en ejercicio de las funciones, propias de las que desempeña en la empresa, o con ocasión de ellas, produce un daño.

\section{CONCLUSIONES}

1. La persona jurídica, específicamente la sociedad mercantil, es susceptible de causar daños, por el actuar de sus órganos, los cuales deben ser resarcidos por la misma sociedad como responsable directa.

2. La legislación especial sobre la materia (Ley $\mathrm{N}^{\mathrm{o}}$ 26887- Ley General de Sociedades), guarda absoluto silencio respecto a la responsabilidad civil de la sociedad mercantil; sus disposiciones sobre responsabilidad por daños, están referidas únicamente a los administradores, no obstante acoger la indicada normatividad a la Teoría Organicista.

3. El artículo $1981^{\circ}$ del Código Civil que es frecuentemente citado por la Judicatura Nacional como fundamento jurídico para resolver los conflictos relativos a las indemnizaciones por daños y perjuicios, no resulta adecuado cuando se trata de las actuaciones dañosas producidas por sus órganos constitutivos, ya que la norma acotada se refiere al daño producido por el dependiente que se hace extensivo a su principal.

4. Las normas que resultan ser aplicables a los supuestos de daños ocasionados por la sociedad mercantil que actúa a través de sus órganos, son las referidas a los artículos $1969^{\circ}$ y demás normas conexas del Código Civil, que contienen el principio general de no causar daño a nadie.

1 Brecia H, Bigliazzi L, Geri U, Natoli F, Busnell, F. Derecho Civil. Tomo I, Vol 1. Bogota: Universidad Externado de Colombia, 1992. pág. 96.

2 Kelsen, H. Teoría Pura del Derecho. México DF, Universidad Nacional Autónoma de México, 1983, págs. 182 a 184.

3 Fernández Sessarego, C. El pensamiento de Cossio y la doctrina contemporánea. En: Derecho PUCP, N 37 , Lima, 1983, págs. 31 a 51.

4 Ferrara, F. Teoría de las Personas Jurídicas. Madrid: Editorial Reus. 1929. págs. 122 a 313.

5 Gierke, citado por Fernández Sessarego, C. El pensamiento de Cossio y la doctrina contemporánea. En: Derecho PUCP, N 37, Lima, 1983, págs. 31 a 51. 
Ana María Aranda Rodríguez - Alcances sobre la

responsabilidad civil en el caso de las sociedades mercantiles

6 Albaladejo, M. Instituciones del derecho Civil. Tomo I, Bosch, 1900, págs. 198 a 200.

7 Op. cit., pág. 201.

8 Ferrara, F Op cit., p 194 y siguientes. Citado por Fernández Sessarego, C. El pensamiento de Cossio y la doctrina contemporánea. En: Derecho PUCP, N 37, Lima, 1983, págs. 31 a 51.

9 Albaladejo, M.Op cit., pág. 100

10 Castan Tobeñas, J Hacia un nuevo derecho civil. Madrid: Editorial Reus, 1933. pág. 90.

11 Galgano, F. El negocio jurídico. Valencia, Tirant lo blanch. 1992, págs. 403 a 425.

12 Albaladejo, M.Op cit. Tomo I. pág. 201

13 Puig Brutau, J. Fundamentos del derecho civil. Tomo I, Volumen I. Barcelona: Bosch, 1979, pág. 259.

14 De Savigny, F. Sistema de derecho romano actual. Segunda edición, Tomo II. Madrid: Centro editorial de Góngora. Pág. 203.

15 Mosset, J. Mandatos. Buenos Aires: Ediar S.A. 1979. pág. 318.

16 Galgano, F. Op cit., págs. 403 a 425

17 Albaladejo, M. Op cit., pág. 356.

18 Visintini, G. Responsabilidad contractual y extracontractual. Lima: ARA Editores. 2002. pág. 85 y siguientes.

19 Elias Laroza, E. Ley General de Sociedades comentada : Ley No. 26887. Trujillo: Normas legales, 1998, págs. 315 a 369 .

20 Artículo $171^{\circ}$.- Los directores desempeñan el cargo con la diligencia de un ordenado comerciante y de un representante leal.

Están obligados a guardar reserva respecto de los negocios de la sociedad y de la información social a que tengan acceso, aun después de cesar en sus funciones.

21 Artículo $166^{\circ}$.- El cargo de director es retribuido. Si el estatuto no prevé el monto de la retribución, corresponde determinarlo, a la junta obligatoria anual.

La participación de utilidades para el Directorio sólo puede ser detraída de las utilidades líquidas y, en su caso, después de la detracción de la reserva legal correspondiente al ejercicio.

22 Elias Laroza, E. Op. cit., págs. 370 a 381.

23 Artículo $187^{\circ}$.- El gerente puede ser removido en cualquier momento por el Directorio o por la junta general, cualquiera sea el órgano del que haya emanado su nombramiento.

Es nula la disposición del estatuto o el acuerdo de la junta general o del Directorio que establezca la irrevocabilidad del cargo de gerente o que imponga para su remoción una mayoría superior a la mayoría absoluta.

24 Artículo $189^{\circ}$.- Son aplicables al gerente, en cuanto hubiere lugar, las disposiciones sobre impedimentos y acciones de responsabilidad de os directores.

25 Artículo $190^{\circ}$.- El gerente responde ante la sociedad, los accionistas y terceros, por los daños y perjuicios que ocasione el incumplimiento de sus obligaciones, dolo, abuso de facultades y negligencia grave. El gerente es particularmente responsable por:

La existencia, regularidad y veracidad de los sistemas de contabilidad, los libros que la ley ordena llevar a la sociedad y los demás libros y registros que debe llevar un ordenado comerciante.

El establecimiento y mantenimiento de una estructura de control interno diseñada para proveer una seguridad razonable de que los activos de la sociedad estén protegidos contra uso no autorizado y que todas las operaciones son efectuadas de acuerdo con autorizaciones establecidas y son registradas apropiadamente.

La veracidad de las informaciones que proporcione al Directorio y la junta general.

El ocultamiento de las irregularidades que observe en las actividades de la sociedad.

La conservación de los fondos sociales a nombre de la sociedad.

El empleo de los recursos sociales en negocios distintos del objeto de la sociedad.

La veracidad de las constancias y certificaciones que expida respecto del contenido de los libros y registros de la sociedad.

Dar cumplimiento en la forma y oportunidades que señala la ley a lo dispuesto en los artículos 130 y 224 . El cumplimiento de la ley, el estatuto y los acuerdos de la junta general y del Directorio.

26 Artículo $177^{\circ}$.- Los directores responden, ilimitada y solidariamente, ante la sociedad, los accionistas y los terceros por los daños y perjuicios que causen por los acuerdos o actos contrarios a la ley, al estatuto por los actos realizados con dolo, abuso de facultades o negligencia grave.

Es responsabilidad del Directorio el cumplimiento de los acuerdos de la junta general, salvo que ésta disponga algo distinto para determinados casos particulares. 
Ana María Aranda Rodríguez - Alcances sobre la responsabilidad civil en el caso de las sociedades mercantiles

Los directores son asimismo solidariamente responsables con los directores que los hayan precedido, por las irregularidades que éstos hubieran cometido si, conociéndolas, no las denunciaren por escrito a la junta general.

27 Artículo $182^{\circ}$.- No obstante lo dispuesto en los artículos precedentes, quedan a salvo las pretensiones de indemnización que puedan corresponder a los socios y a los terceros por actos de los directores que lesionen directamente los intereses de aquellos. No se considera lesión directa la que se refiere a daños causados a la sociedad, aunque ello entrañe como consecuencia, daño al accionista.

28 Artículo $183^{\circ}$.- La demanda en la vía civil contra los directores no enerva la responsabilidad penal que pueda corresponderles.

29 Artículo $191^{\circ}$.- El gerente es responsable, solidariamente con los miembros del Directorio, cuando participe en actos que den lugar a responsabilidad de éstos o cuando, conociendo la existencia de esos actos, no informe sobre ellos al Directorio o a la junta general.

30 Diccionario de la Real Academia Española. 22 ed. 2001, citado por Patron, C. ¿amo o sirviente?, consideraciones funcionales en torno a la responsabilidad vicaria a propósito del artículo $1981^{\circ}$ del Código Civil. En Themis $N^{\circ} 50$, revista editada por alumnos de la Pontificia Universidad Católica del Perú. 2005, pág. 284.

31 Artículo $1981^{\circ}$.- Aquel que tenga a otro bajo sus órdenes responde por el daño causado por este último, si ese daño se realizó en el ejercicio del cargo o en cumplimiento del servicio respectivo. El autor directo y el autor indirecto están sujetos a responsabilidad solidaria.

32 Revoredo, D. Código Civil. Exposición de motivos y comentario. Tomo VI. Lima: Ocurra Editores S.A. 1985. pág. 805 .

33 Espinoza, J. Derecho de la responsabilidad civil. 2da ed. actualizada. Lima: Gaceta Jurídica. 2003, págs. 284 a 285 .

34 Espinoza, J. Op cit., págs. 286 a 287. 